Estudios de la Paz y el Conflicto

Revista Latinoamericana

IUDPAS-UNAH

Volumen 1, Número 2, pp. 55-78

ISSN-e: 2707-8922 | ISSN: 2707-8914

DOI: $10.5377 /$ rlpc.v1i2. 9833

Julio-diciembre 2020

\title{
ESTRATEGIAS DE COMUNICACIÓN DE LA NUEVA EXTREMA DERECHA ESPAÑOLA. DE HOGAR SOCIAL A VOX, DEL ALTER- ACTIVISMO A LA DOCTRINA DEL SHOCK
}

\author{
COMMUNICATION STRATEGIES OF THE NEW SPANISH FAR RIGHT. FROM \\ HOGAR SOCIAL TO VOX, FROM ALTER-ACTIVISM TO THE SHOCK DOCTRINE
}

\begin{abstract}
Antonio Álvarez-Benavides
City University of New York (CUNY)

Grupo de Estudios Socioculturales Contemporáneos (GRESCO-UCM)

Centre d'Analyse et d'Intervention Sociologique (CADIS-Internacional)

alvarezbenavides@gmail.com

Francisco Jiménez Aguilar

IPAZ, Universidad de Granada

fjja@correo.ugr.es
\end{abstract}

Recibido: 22-04-2020

Aceptado: 05-05-2020

Cómo citar / citation

Álvarez-Benavides, A., y Jiménez Aguilar, F. (2020). "Estrategias de comunicación de la nueva extrema derecha española. De Hogar Social a Vox, del alter-activismo a la doctrina del shock", Estudios de la Paz y el Conflicto, Revista Latinoamericana, Volumen 1, Número 2, 55-78. DOI: $10.5377 /$ rlpc.v1i2.9833

\section{Resumen}

Desde la Transición democrática la extrema derecha apenas tenía representatividad política y soporte popular en España, lo que suponía una excepción respecto al contexto europeo. Sin embargo, desde hace apenas unos años, dos nuevas ultraderechas han irrumpido con fuerza: Hogar Social y Vox. En este texto analizaremos la evolución de la extrema derecha española desde una perspectiva histórica y sociológica para explicar el surgimiento de ambas formaciones. A través de la netnografía y el análisis del discurso examinaremos sus similitudes y diferencias, sus tácticas comunicativas y los motivos que podrían explicar su creciente aceptación por una parte significativa de la sociedad.

Palabras clave

Extrema derecha; tácticas discursivas; netnografía; alter-activismo; doctrina del shock. 


\begin{abstract}
The Spanish far-right has not had political representation or popular support since the democratic Transition, which was an exception to the European context. However, since just a few years ago, two new ultra-rightists formation have burst in force: Hogar Social and Vox. In this text we will analyze, from a sociological and historical perspective, the evolution of the Spanish far-right with the aim of explaining the emergence of both formations. In the same way, through a netnography and a discursive analysis, we will examine their similarities and differences, their communicative tactics and the reasons that could explain their growing acceptance by a significant part of society.
\end{abstract}

\title{
Keywords
}

Far right, communication strategies; netnografy; alter-activism; the shock doctrine.

\section{INTRODUCCIÓN}

El auge de la extrema derecha se ha convertido en un asunto central a nivel internacional y, desde finales de 2018, en un tema que también afecta a España. A nivel europeo, desde los años 70, la extrema derecha se reconfiguró en la llamada Nouvelle Droit, una derecha que pretendía separarse de las ideas fascistas para articular un ideario nacionalista radical, conservador y antinmigración, que aceptaba las reglas del juego democrático y que, poco a poco, fue generando distintos colectivos intelectuales, sociales y políticos en distintos países (Ignazi, 1992). Quizá el caso más reconocible sea el lepenismo en Francia que es un buen ejemplo de cómo esta nueva ultraderecha ha ido evolucionando en los últimos 40 años, modernizándose y acaparando cada vez más presencia en Europa (Gallego, 2007; European Parliament, 2019; Holger y Manow, 2019). En el siglo XXI los partidos políticos de extrema derecha han crecido en la eurozona de manera sostenida (Mayer, 2018; Casals, 2011), estando presentes en 18 parlamentos nacionales europeos y representando, al menos, un 10\% del electorado en la mayoría de éstos (Holger y Manow, 2019). A nivel internacional la situación es similar. El caso más notable es el gobierno de Donald Trump en Estados Unidos, abiertamente ultranacionalista, antinmigración e islamófobo. En Brasil, Jair Bolsonaro ha adquirido notoriedad internacional por la radicalidad de sus medidas y por el retroceso dramático en derechos sociales tan básicos como la libertad ideológica o sexual. En otros países de Latinoamérica como Chile, Costa Rica, Colombia, Guatemala, México, Nicaragua o Venezuela la extrema derecha es cada vez más poderosa (Weld, 2020). Pero también en países como Filipinas, Pakistán, Turquía, Tailandia, Japón (Toscano, 2019) o Australia (Hutchinson, 2019).

España ha sido considerada durante décadas como una "excepción" ya que, desde la transición de la dictadura franquista a la democracia, la extrema derecha no ha llegado a tener ni representatividad política ni suficiente apoyo ciudadano (González-Enríquez, 2017; Alonso y Rovira, 2015). La vinculación de la extrema derecha con el franquismo, la falta de renovación de su ideario político, la carencia de un proyecto común y su alineación con acciones y grupos violentos son algunos de los factores que explicaban esta excepcionalidad (Rodríguez, 2012). Sin embargo, con la llegada del nuevo milenio, surgieron grupos de extrema derecha al estilo europeo, como Plataforma per Catalunya o España 2000, que abandonaron la estética militar y skinhead, los discursos y la simbología franquista, y que 
experimentaron cierto éxito en el ámbito municipal con un discurso antinmigración y de defensa de lo español (Hernández-Carr, 2011; Sánchez y Rodríguez, 2013). A la estela de estas formaciones, en la última década, han irrumpido Vox, convirtiéndose en el primer partido político de extrema derecha español presente en los parlamentos autonómicos y en el nacional en más de 30 años, y otros colectivos, como Hogar Social Madrid, más cercanos a los movimientos sociales y que cuenta con delegaciones en distintas ciudades españolas, así como toda una serie de asociaciones culturales "hermanas" (Jiménez y Álvarez-Benavides, 2019).

En este texto analizaremos las nuevas formas de extrema derecha que representan Hogar Social y Vox en España. Para ello, prestaremos especial interés a su discurso, sus estrategias y sus tácticas para intentar dilucidar las claves de su auge, su consolidación y el aumento de sus apoyos por parte de la ciudadanía. Finalmente, explicaremos algunas de las claves que hasta el momento están caracterizando su acción durante la pandemia del COVID-19.

\section{METODOLOGÍA}

Este artículo es fruto de una investigación llevada a cabo durante los últimos cinco años sobre el surgimiento de nuevas formas de extrema derecha en España desde una perspectiva histórica y sociológica. Analizar la extrema derecha tiene sus propias limitaciones, la primera de ellas es el hermetismo y la negativa a participar por parte de sus miembros y colectivos en este tipo de investigaciones (Toscano, 2019). A pesar de ello se llegaron a hacer algunas entrevistas durante 2018 y principios de 2019, pero la negativa a que éstas fueran grabadas y utilizadas hizo que se optara por presentar los resultados del análisis cualitativo de su primer nivel discursivo, esto es, su discurso público (Albanese et al., 2014). Para ello se ha utilizado la técnica de la netnografía, también conocida como etnografía digital (Pink et al. 2016), etnografía virtual (Hine, 2004) o ciberantropología (Vázquez, 2008). La netnografía es una técnica de corte antropológico de análisis de redes que se utiliza para el estudio de comunidades, grupos e individuos, sus identidades, interacciones y conflictos, entre otros, y que tiene como campo de acción social Internet. Aunque esta técnica solía asociarse con los estudios de mercado y de marketing (Kozinets, 2010), su extensión ha sido muy rápida a otros campos de la investigación social como la antropología, la psicología y la sociología. La técnica es similar a la etnografía clásica pero adaptada al contexto de la Red, siendo la observación participante y no participante uno de sus elementos centrales. Desde el nacimiento y desarrollo de las redes sociales se ha vuelto una herramienta casi imprescindible para analizar este tipo de organizaciones y sus interacciones (Hooley et al., 2012). Es una metodología con mucho potencial para la sociología de los movimientos sociales y la sociología política, siendo las redes sociales uno de los ámbitos más importantes del activismo contemporáneo (Castells, 2012).

La primera parte de la netnografía consistió en realizar un seguimiento semanal de las cuentas de Facebook, Twitter y YouTube de Hogar Social y Vox, sus distintas delegaciones y sus líderes. Al tratarse de una investigación de varios años y con distintos objetivos, durante la netnografía se ha hecho un seguimiento de muchos colectivos, partidos políticos y líderes de la extrema derecha española, incluso de otros partidos y políticos que no perteneciendo a la extrema derecha han realizado comentarios, propuestas o afirmaciones cercanas a esta ideología y que han sido recogidos en otros trabajos (Álvarez Benavides, 2019; 2018; 
Jiménez y Álvarez-Benavides, 2019). Para este texto el análisis se ha acotado a las dos nuevas extremas derechas (Hogar Social -Madrid, Toledo, Granada y Zaragoza- y Vox -Nacional, Madrid y Andalucía-) y a sus dos líderes (Melisa Domínguez Ruíz, de Hogar Social, y Santiago Abascal Conde, de Vox, antiguo militante y político del Partido Popular).

Para el tratamiento de un volumen de información tan alto se han utilizado las herramientas MessageSaver y Twlets que permiten descargar la información y tratarla en bases de datos. No obstante, el análisis no pretende en ningún caso tener una dimensión cuantitativa, por lo que no ha habido ninguna explotación estadística de los datos obtenidos. Se ha realizado un análisis del discurso "clásico", buscando las líneas discursivas fundamentales hasta obtener saturación discursiva (Ibáñez, 1985). El análisis es de carácter comparativo, por lo que se ha incidido en cómo cada una de las formaciones estudiadas se posiciona en torno a las distintas líneas ideológicas analizadas y cómo articulan sus distintas estrategias de comunicación.

También se han incluido otras fuentes como entrevistas, declaraciones y noticias aparecidas en medios de comunicación, tanto periódicos como televisiones nacionales, que nos han permitido acceder a su discurso público desde otros medios no afines. Por último, se han utilizado fuentes secundarias de corte cuantitativo y demoscópico, principalmente a través de la consulta y el tratamiento de datos de distintos barómetros de opinión que publica mensualmente el Centro de Investigaciones Sociológicas (CIS) ${ }^{1}$ - enero y julio de 2019, enero de 2020 y las series históricas sobre autoubiación ideológica-, datos del Parlamento Europeo -Eurostat- (2019), del Ministerio del Interior (2020), Ministerio de la Presidencia (2019) y de The Parliament and Government Composition Database -ParlGov- (Holger y Manow, 2019), así como de iniciativas y empresas privadas de reconocido prestigio como Metroscopia (2018), Sociométrica (2019) o IMOP Insights (Panelconfindecial, 2018) para acceder a las características sociológicas de sus simpatizantes y a su evolución electoral en los últimos meses.

\section{LAS NUEVAS EXTREMAS DERECHAS ESPAÑOLAS}

Definir y delimitar la extrema derecha resulta complicado. En primer lugar, porque en raras ocasiones un colectivo, un partido o un individuo se autodefinen como de extrema derecha, ultraderechista o fascista. En segundo lugar, porque en ámbitos no académicos se utilizan indistintamente, y a veces como sinónimos, términos como fascismo, extrema derecha o neofascismo, entre otros. En tercer lugar, porque en España este tipo de términos y definiciones, más allá del campo de estudio en el que se empleen, tienen una importantísima carga simbólica. El peso de la Guerra Civil española, el franquismo y la imagen pública de

\footnotetext{
${ }^{1}$ Los barómetros del CIS consisten en una serie de encuestas que se realizan mensualmente (excepto en agosto), para media la opinión pública española sobre diversos temas. Para ello se entrevista en torno a 2.500 personas del territorio nacional elegidas aleatoriamente, de las que, además de sus opiniones, se recoge información social y demográfica para el análisis. El barómetro establece una serie de preguntas fijas con las que se elaborar "indicadores del barómetro" y series históricas, además de otra serie de preguntas variables con temas de interés social o político del momento. Los meses de enero, abril, julio y octubre los barómetros incluyen un conjunto de preguntas fijas sobre actitudes políticas a partir de las que el CIS calcula y publica la estimación de voto. Los resultados de los barómetros pueden consultarse en la web del CIS (http://www.cis.es/cis/opencm/ES/11 barometros/index.jsp) en el apartado de avance de resultados. Además, en el Banco de Datos del CIS se pueden encontrar distintos ficheros con microdatos de cada estudio. Estudios de la Paz y el Conflicto, Revista Latinoamericana, IUDPAS-UNAH, Volumen 1, Número 2, julio-diciembre 2020, pp. 55-78. DOI: $10.5377 /$ rlpc.v1i2.9833
} 
los colectivos ultraderechistas surgidos durante la Transición, evocan una historia de conflicto, violencia y represión que no puede desligarse del imaginario colectivo y que complica su uso académico, especialmente en ciencias sociales.

Del mismo modo, resulta problemático señalar qué partidos políticos o agrupaciones estarían dentro de lo que entendemos por extrema derecha. Aunque exista mucha variabilidad, objetivos y contextos dentro de la extrema derecha europea, la investigación reciente sugiere la existencia de una serie de puntos comunes. El primero de ellos es el ultranacionalismo, ligado a altos niveles de xenofobia y que combinados se articulan en torno al llamado identitarismo (Sebastian, 2018). Le sigue la defensa de la tradición, una tradición inventada, (re)construida y (re)articulada en torno a un pasado idealizado que se ha perdido o que ha sido usurpado (Hobsbawm y Ranger, 2012). A través de un discurso pesimista sobre el presente se culpa de dicha usurpación a la inmigración y al multiculturalismo (en ese sentido, los colectivos culpables de la degradación de la nación son variados, pero destacan los judíos y, en especial, los musulmanes), pero también a la pérdida de los valores asociados a esa tradición. Todo ello conlleva además un discurso ultraconservador, de defensa de la familia tradicional, en contra del feminismo o los colectivos LGBTI. Por último, la crítica a las políticas y los políticos poco contundentes con la defensa de lo nacional, por lo que abogan por un Estado centralizado, autoritario e intervencionista (Hernández-Carr, 2011: 144-148; Mudde, 2007).

En España podemos identificar todas estas características en varios movimientos sociales y políticos, aunque con características propias. Por ejemplo, la exaltación de la nación, de sus símbolos y de la defensa de la primacía de los nacionales, se complementa con la defensa de un Estado autoritario y centralizado en el que deben suprimirse las comunidades autónomas. En este sentido y dentro del ideario anti-diversidad, además del rechazo al multiculturalismo (antinmigración, anti-musulmanes y, en ciertos casos, antisemitas), a la diversidad sexual (anti-LGTBI, defensa de la familia tradicional), se desdeña la diversidad étnica y lingüística de las distintas regiones del país. De la misma manera que el contexto español presenta diferencias respecto al contenido ideológico de la extrema derecha europea, también existe una variabilidad en los tipos de extrema derecha. Piero Ignazi (2003) clasifica la extrema derecha europea en dos grandes grupos que se dividen desde los años ochenta. El primero sería la "extrema derecha tradicional", que no se desliga completamente del fascismo y que cada vez es menos representativa; el segundo grupo, la llamada "nueva extrema derecha" o "extrema derecha postindustrial" que rompe con ese pasado, reformulándose y aceptando las reglas del juego democrático.

En el caso español esta subdivisión es algo más compleja, sobre todo en las formaciones nacidas en la última década. Por un lado, sigue habiendo grupúsculos neonazis y neofascitas, que se autodefinen como tales, no aceptan la democracia y no dudan en utilizar la violencia directa para defender sus ideas. Aunque su presencia es sobre todo relevante en ciertos eventos deportivos y en manifestaciones esporádicas, se han articulado en torno a algunas formaciones políticas minoritarias, entre las que destaca Alianza Nacional. Por otro lado, partidos clásicos, como la Falange Española o Falange de las $\mathrm{JONS}^{2}$, y aquéllos surgidos

\footnotetext{
${ }^{2}$ Falange Española de las Juntas de Ofensiva Nacional Sindicalista (FE de las JONS). Partido fundado en 1976 para recoger la herencia política de la dictadura franquista y el "partido único", rechazando la vía democrática y proponiendo la violencia como forma de protesta durante la Transición. Desde los años ochenta inició un viraje para distanciarse del fascismo y la figura de Franco, reivindicando un falangismo renovado y aceptando Estudios de la Paz y el Conflicto, Revista Latinoamericana, IUDPAS-UNAH, Volumen 1, Número 2, julio-diciembre 2020, pp. 55-78. DOI: 10.5377/rlpc.v1i2.9833
} 
durante los años de la Transición como Fuerza Nueva o el Movimiento Católico Español, con una ideología abiertamente neofranquista, pero que aceptan la democracia. Además, desde la primera década del 2000, surge la llamada "nueva extrema derecha", integrada por distintas formaciones entre las que hoy sobresale Vox, que además adopta características de otras experiencias internacionales como la alt-right americana. Por último, hablaríamos de un cuarto tipo, la denominada alter-derecha o el alter-activismo de extrema derecha, donde destaca Hogar Social, cuya proyección es muy similar a la de otras organizaciones europeas como CasaPound Italia y Amanecer Dorado en Grecia.

\subsection{La extrema derecha ultraliberal: Vox}

El partido político Vox fue fundado a finales del 2013 por miembros ultraconservadores del Partido Popular, pero ha irrumpido realmente en el escenario político a partir de las elecciones autonómicas andaluzas de 2018, en las que obtuvo 12 escaños. Aceptan la democracia, evitan, en gran medida, las referencias visuales, discursivas e ideológicas al franquismo y aunque hay coincidencias y se relaciona con partidos de extrema derecha europeos como el Frente Nacional, la Liga Norte y el Partido por la Libertad en Polonia, el espejo en el que se han fijado ha sido la derecha estadounidense, principalmente en Donald Trump. Esta referencia no es casual, sino estratégica, pues se presentan como un partido sin complejos, alejado de la vieja derecha europea, utilizando unas formas y unos discursos novedosos, como afirma Rafael Bardají, uno de los ideólogos de la formación:

Con Le Pen hay pocas coincidencias, no podemos olvidar que los franceses nos invadieron. Y la cultura política francesa es estatista. Nos parecemos más a Trump, en su guerra cultural con lo establecido, con lo politicamente correcto, con esa filosofia de que todo tiene que ser consensuado, soft, blando. Coincidimos en el «América, primero». España y los españoles, primero (Martínez, El Mundo, 04/02/2019).

Una de las características fundamentales de Vox es la "incorrección política" y la ruptura con ciertos límites éticos o deontológicos habituales en la política española (Nagle, 2017). En la misma línea que Trump y su ideólogo Steve Bannon (Enli, 2017), el leguaje de Vox es directo, descomedido y tiene como objetivo llegar a un público desencantado, no solo al votante tradicional de la extrema derecha.

Aunque Vox no se autodefina como un partido de ultraderecha, su votante prototípico es un hombre de mediana edad, situado ideológicamente en la extrema derecha, conservador, ultranacionalista, xenófobo y antifeminista. Estudios realizados por Metroscopia (octubre, 2018), el barómetro del CIS (enero y julio, 2019) o Sociométrica (Mayo, 2019), muestran que el votante de Vox se sitúa entre el punto 7 y el 9 de la escala ideológica 0-10 (0, extrema izquierda y 10, extrema derecha), su edad media ronda los 45 años y es mayoritariamente varón, casi el 75\%. El motivo principal para votar a Vox (para casi el $90 \%$ de sus votantes en las elecciones andaluzas) es la crisis de Cataluña y la apuesta por la disolución de las autonomías, seguido del problema de la inmigración y, por último, como respuesta al feminismo (IMOP Insights, diciembre 2018). Los motivos de su crecimiento son múltiples, el descontento y agotamiento de un sector importante de la derecha española con el Partido Popular, la crisis catalana, el alargamiento de los efectos de la crisis o el avance del

las reglas de juego democrático para poder defender su concepción antidemocrática de la política. Sus resultados electorales han sido testimoniales.

Estudios de la Paz y el Conflicto, Revista Latinoamericana, IUDPAS-UNAH, Volumen 1, Número 2, julio-diciembre 2020, pp. 55-78. DOI: $10.5377 /$ rlpc.v1i2.9833 
feminismo. Pero sin duda, a esto hay que sumarle el uso de los medios de comunicación, tanto los tradicionales como digitales, y la utilización de nuevas estrategias comunicativas ya ensayadas por la extrema derecha en otros países (Caiani y Parenti, 2013).

\subsection{La ultraderecha alternativa: Hogar Social}

Si Vox es actualmente el gran referente de los partidos de extrema derecha en España, Hogar Social representa su articulación más novedosa en España. Junto con toda una serie de colectivos surgidos en los últimos años han configurado una "extrema derecha alternativa", más cercana a la lógica del activismo de los movimientos sociales que a los partidos políticos tradicionales. Al igual que Vox, estos colectivos no se autodenominan como ultraderecha, sino como asociaciones de ayuda a los nacionales, de tipo cultural y juvenil. Sus líderes son en su mayoría jóvenes menores de 30 años. Sus estrategias comunicativas se basan en la combinación del uso sistemático de las redes sociales y de acciones a nivel local. Para ello, imitando las estrategias de otros grupos como el italiano CasaPound, el partido griego Amanecer Dorado o el francés Le Bastion Social, han suavizado primero su apariencia, evitando cualquier tipo de simbología fascista, y después su discurso, alejándolo, aparentemente, del odio y de la violencia, para formularlo en torno a una idea fundamental: el identitarismo, es decir, la defensa de los derechos de los nacionales por encima de los extranjeros.

En Hogar Social hay una clara intencionalidad de dar una nueva imagen a la ultraderecha con un tratamiento particular de las formas, los discursos y los espacios, para ampliar sus apoyos en distintas capas sociales, especialmente entre los jóvenes en situación de precariedad. El adoctrinamiento y la socialización ya no se reduce a los campos de fútbol o los locales clandestinos donde se reunían los antiguos militantes de extrema derecha, sino también a través de Internet, en el día a día en los barrios, en los espacios de cotidianidad. Sus miembros, al menos una parte de ellos, no se sienten pertenecientes a grupos xenófobos, excluyentes o violentos, sino de ayuda a los españoles en situación de exclusión o precariedad. Una parte de su tiempo lo dedican a difundir su pensamiento y planificar nuevas acciones de protesta más efectivas.

Estos colectivos han sido denominados fascismos à la carte (Albanese et al., 2014; Di Nunzio y Toscano, 2011), es decir, extremas derechas que cogen los elementos más desdeñables de esta ideología y los ocultan, al tiempo que imitan las tácticas comunicativas y la dimensión cultural de movimientos alternativos progresistas, como el movimiento altermundialista o el 15M, para resultar más amables, más atrayentes, y de esa manera lograr más simpatizantes.

\section{NODOS, CARACTERÍSTICAS Y TÁCTICAS DISCURSIVAS}

La característica fundamental que aúnan las extremas derechas españolas es la exaltación de lo propio en contraposición y detrimento de lo ajeno. El ultranacionalismo que defienden surge de una definición arbitraria, particular y restrictiva del ser nacional (Pérez-Agote, 1993), y se contrapone a cualquier otra definición y a todos los que están fuera de los límites

de ese ser nacional. Tanto para Vox como para Hogar Social el elemento central de su ideología es su definición particular de lo que es ser español. Una definición que no es 
cuestionable y a partir de la que se articula el resto de su ideario: “¿Un español? Yo creo que todos sabemos lo que es un español. Yo no creo que sea algo que por la corrección política a día de hoy haya que matizar" (Melisa Domínguez, La Contra TV, 16/03/2017).

Existe un rechazo abierto hacia la diversidad, tanto dentro como fuera de su concepto particular de nación y, por extensión, de lo español. Así, no solo hay una defensa a ultranza de España y de la nación española, como en otros partidos conservadores o nacionalistas, sino que dentro de esa definición no caben gitanos, homosexuales, feministas, comunistas, españoles no cristianos o cuyo origen familiar sea extranjero (esto último sobre todo en Hogar Social). Es decir, esta definición de lo nacional tiene un carácter político, pero también étnico, así como una restricción endógena y exógena. Además de un discurso antinmigración o islamófobo, los límites de lo español se aplican de igual modo a los connacionales, a cualquier tipo de identidad colectiva religiosa, sexual y política, o de carácter étnico, lingüístico, cultural o regional.

Este discurso se reproduce en las redes sociales, donde la extrema derecha ha desembarcado con fuerza, en los medios de comunicación tradicionales, en sus mítines y en sus acciones a nivel local. Se articula en torno a distintos ejes (antinmigración, antimusulmanes, antifeminismo, anti-LGTBI y en contra de los nacionalismos regionales y de la diversidad étnica y lingüística española) y se sustenta en una serie de estrategias discursivas (utilización de chivos expiatorios, victimismo combinado con hipérboles, mensajes catastrofistas, fake news y bulos, entre otros).

\subsection{La exaltación de lo español}

La exaltación de lo español tiene dos grandes campos de acción. El primero es desde 2017 la independencia de Cataluña. Todos los grupos de extrema derecha han hecho una intensa campaña en contra de la "ruptura de España", a través de las redes sociales, convocando manifestaciones en distintas ciudades, pidiendo la cárcel para los políticos independentistas, reclamando la ilegalización de sus partidos, llamando a la lucha por la defensa de España y alentando la violencia policial durante las manifestaciones independentistas. Aunque este mensaje ha estado presente en otros partidos o líderes de derechas, centro e incluso de izquierdas, la solución para Vox y para Hogar Social no pasa exclusivamente por la recuperación del orden constitucional, sino por la supresión total de las autonomías. Si bien son muchos los políticos que han pedido la utilización sistemática del artículo 155 de la Constitución española que permitiría la supresión de la autonomía de Cataluña, Santiago Abascal directamente pidió la proclamación del Estado de excepción y sitio (artículo $116 \mathrm{CE}$ de 1978), además del envío de guardia civil, policía nacional, militares (@Santi_ABASCAL, 01/10/2018 y 09/12/2018), además de la ilegalización del partido político de izquierda Podemos por apoyar a los independentistas (Arjona, Cope, 10/10/2018). La presencia de Hogar Social ha sido más intensa y combativa en las calles con acciones de tipo simbólico, algo recurrente dentro de sus estrategias de comunicación, por ejemplo, poniendo lazos azules por la defensa de la unidad de España durante los meses de octubre y noviembre de 2018, en contraposición a los lazos amarillos que simbolizan la solidaridad con los presos políticos catalanes.

La segunda forma en la que se exalta lo español es a través de la mitificación del pasado y de la identidad española, recuperando personajes y momentos históricos que representan un pasado glorioso que se está perdiendo. Hogar Social recurre en varias ocasiones a Don

Estudios de la Paz y el Conflicto, Revista Latinoamericana, IUDPAS-UNAH, Volumen 1, Número 2, julio-diciembre 2020, pp. 55-78. DOI: 10.5377/rlpc.v1i2.9833 
Quijote y a frases del libro de Cervantes en sus entradas en Facebook (31/10/2016) y emplea otras expresiones del acervo popular como "combate al enemigo imbatible" y "si los perros ladran es que avanzamos" (@HogarSocialTol, 29/08/18), frases también recurrentes en los discursos de Santiago Abascal (@Santi_ABASCAL, 16/09/2014 y 28/11/2018). Esta recuperación de lo español se articula además en oposición a lo extranjero y más concretamente a los musulmanes. La nación se construye sobre una historia inventada, reeditada a partir de una visión particular de ésta, como "comunidad imaginada" (Anderson, 1991), con unos intereses políticos particulares que les permiten disputar la concepción de España. Conforme a ello, el nacimiento de la nación surge bajo los Reyes Católicos en contraposición a los musulmanes, aunque es también una nación recuperada, preexistente al periodo islámico. Por ello, la conmemoración de la Toma de Granada ${ }^{3}$ es un acontecimiento cada vez más celebrado por la ultraderecha. "Decir que España se constituye frente a los invasores musulmanes es una realidad histórica. La toma de Granada es un hito", defendió Rafael Bardají en la prensa (Martínez, El Mundo, 04/02/2019). La vindicación y la utilización de la "Reconquista" ${ }^{4}$ " es un elemento central en el imaginario de Vox y ha sido recurrente su uso en campañas electorales, como en la autonómica de Andalucía de 2018, donde publicó un vídeo en el que anunciaba "la Reconquista comenzará en tierras andaluzas" con Santiago Abascal montado a caballo como el hacedor de la Reconquista de España (@voxnoticias_es, 12/11/2018). Igualmente, la campaña por las primeras elecciones generales de 2019 comenzó en Covadonga, presentando a Abascal como una suerte de Don Pelayo contemporáneo ${ }^{5}$ (Youtube, Vox España \#PorEspaña, 13/04/2019). De esta manera, por un lado, plantean un discurso catastrofista y victimista, la España que se perdió y que se ha vuelto a perder, identificando al culpable o chivo expiatorio de esta situación (la inmigración y concretamente los musulmanes). Por otro, se posicionan como los reconquistadores y salvadores de la nación.

Tanto Vox como Hogar Social son abiertamente islamófobos, convirtiendo a los musulmanes en el chivo expiatorio al que recurren tanto para argumentaciones internas como externas: son los culpables de poner en riesgo la identidad europea (la perversión del multiculturalismo), de la crisis económica (aumentan el paro al quitar trabajo a los españoles, copan las ayudas sociales y destruyen el Estado de bienestar), de convertirnos en una minoría étnica (alta natalidad) e, incluso, de exterminarnos (terrorismo).

En su cosmovisión, el Estado y el gobierno son cómplices de esta situación, que se agrava con su política de refugiados. Hogar Social reparte alimentos "solo para españoles" y es especialmente beligerante con la política de refugiados, que relaciona con el aumento de la pobreza, pero también con el terrorismo global: "El Islam destruye Europa mientras le abrimos las puertas \#terroristaswelcome"(@HogarSocial_, 17/08/17). Para ello utiliza

\footnotetext{
${ }^{3}$ En la ciudad de Granada, España, se celebra cada 2 de enero la rendición del sultán Boabdil en esa misma fecha en el año 1492. Desde el comienzo de la dictadura franquista esta fiesta ha adquirido un marcado carácter nacionalista que después de 1975 ha sido aprovechado por grupos de extrema derecha para congregarse y hacer explícitas algunas de sus reivindicaciones políticas.

${ }^{4}$ La idea de "reconquista" se refiere comúnmente al proceso de guerra y expulsión de los musulmanes de la Península Ibérica por los diferentes reinos cristianos. Desde finales del siglo XVIII ha sido empleada de forma recurrente por el nacionalismo español de raíz conservadora como uno de los mitos fundacionales de España y justificativo de su carácter católico.

${ }_{5}^{5}$ Personaje histórico considerado el primer líder del Reino de los astures al que suele asociarse los orígenes nacionales míticos de España. La mayoría de estas apropiaciones nacionalistas suelen destacarlo por su carácter marcial, cristiano y antimusulmán.

Estudios de la Paz y el Conflicto, Revista Latinoamericana, IUDPAS-UNAH, Volumen 1, Número 2, julio-diciembre 2020, pp. 55-78. DOI: $10.5377 /$ rlpc.vli2.9833
} 
imágenes explícitas, mostrando víctimas de atentados, lapidaciones, decapitaciones. Con los refugiados Vox presenta otros matices, intentando articular un mensaje algo más ambiguo y que no parezca racista a ojos de la opinión pública. Por ejemplo, Santiago Abascal propuso "20 propuestas para la victoria en la Guerra Total contra el fundamentalismo islámico, y la salvación de occidente", usando el hashtag \#Covadonga (@Santi_ABASCAL, 19/11/15), entre las que destacaban: la "cadena perpetua para los terroristas apresados vivos", la "retirada de nacionalidad para cualquier persona que por cualquier medio muestre su apoyo al yihasimo", intervenciones militares, cierre de mezquitas y abandono del modelo multicultural. Al mismo tiempo pidió la "solidaridad con las víctimas de atentados y con los verdaderos refugiados", además de un "cambio drástico en política sobre refugiados priorizando refugiados cristianos, yazadíes y otras minorías perseguidas". Es decir, intentan plantearlo como una cuestión política que no remita abiertamente a ideas supremacistas o racistas, aunque sean éstas las ideas que subyacen en su discurso. También Hogar Social intenta blanquear su xenofobia en las redes con mensajes que remiten a cuestiones más políticas que étnicas, por ejemplo, en una entrada en la página de Facebook de Hogar Social Granada (20/09/2018) acompañada de una imagen y una noticia sobre el rescate de 243 personas -entre ellas diez menores- en aguas del Mediterráneo escribían: "miles de personas se juegan la vida mientras las mafias y las ONGs se lucran. Los trabajadores españoles sufren el efecto de la inmigración. ¿A quién beneficia esta situación?”.

\subsection{Defensa de la familia tradicional, antifeminismo y “White Male Revolt”}

El antifeminismo se ha convertido en uno de los vectores de la nueva extrema derecha, especialmente de Vox, que defiende un modelo tradicional de familia, una concepción patriarcal de las relaciones de género y del papel de la mujer en la sociedad, por lo que ha encontrado en los hombres descontentos ante el avance de los derechos de las mujeres y la pérdida de sus privilegios una fuente importante de apoyo.

En 1997 Peter Merkl hablaba de la llamada White Male Revolt (1997: 5), para describir "la revuelta del hombre blanco" ante la disolución del orden social tradicional. La crisis de la masculinidad y el deseo de volver a una concepción tradicional y orgánica de la familia que comportase la pervivencia de los roles tradicionales de los hombres y las mujeres explicaría que el voto a la extrema derecha sea en las últimas décadas eminentemente masculino (Givens, 2004; Casals, 2015: 9). Por extensión, todo aquello que implique la ruptura con esta tradición, como las nuevas familias, el reconocimiento de los derechos de la mujer y la comunidad LGTBI o las parejas y familias de distintos orígenes étnicos deberían ser evitados en la medida de lo posible.

Vox ha desplegado y combinado un gran abanico de estrategias comunicativas tratando de seducir y "rescatar" a aquellos colectivos conservadores que siguen mostrando resistencias y oposición a reconocer la desigualdad de la mujer y la pervivencia del patriarcado, rehabilitándoles socialmente y normalizando su ideario machista (Kelly, 2017). Desde la incorrección política, Vox ha tratado temas como la violencia de género, que, aun teniendo un gran consenso social, produce resistencias en un colectivo minoritario, pero que puede ser un electorado potencial de la formación. Para ello se han movido en el ámbito de la postverdad, utilizando noticias falsas (fake news), bulos, datos exagerados o directamente falsos, con un tema que conlleva altas dosis de emotividad (Allcott y Gentzkow, 2017). Para reforzar esa dimensión emotiva, victimizan a los hombres y la concepción tradicional de la 
familia, perseguidos y socavados supuestamente por leyes injustas, una falsa noción de progreso y la perversión de la tradición nacional por parte del feminismo. Un ejemplo paradigmático y en el que se combinan todas estas líneas argumentativas y estrategias de comunicación, son las declaraciones del líder de Vox (Bans, Intereconomía, 04/10/2018) en las que afirmaba que "las mujeres que han sido asesinadas en España han sido, mayoritariamente, a manos de extranjeros". Por un lado, se utiliza al chivo expiatorio de la inmigración, culpabilizando a los inmigrantes por pervertir la cultura española y sus logros sociales al portar costumbres y tradiciones retrógradas y eminentemente violentas con las mujeres. Por otro lado, la victimización del hombre español, que se ve sojuzgado por unos hechos que no son ciertos, es decir, el feminicidio, y que en caso de serlo no serían su responsabilidad porque son cometidos en su mayoría por extranjeros. Éste sería además un ejemplo claro de postverdad o mentira emotiva, ya que utiliza un tema sensible, que apela a sentimientos profundos, que se apoya en una percepción negativa de la inmigración y que utiliza datos tergiversados o directamente falsos (Lockie, 2017), como muestran los informes anuales sobre los asesinatos por violencia machista (Ministerio de la Presidencia, 2019).

En el caso de Hogar Social el antifeminismo se basa, principalmente, en la crítica a las leyes de igualdad y al feminismo "radical", poniendo en duda algunas de las discriminaciones básicas de las mujeres, especialmente en el ámbito laboral, como el techo de cristal o las diferencias salariales. Éste es, también, un elemento importante de su ideario y ocupa un lugar destacado tanto en sus mensajes en las redes sociales como en sus acciones en las calles. De hecho, el tweet que Melisa Domínguez ha tenido fijado en su cuenta personal de Twitter durante varios meses de 2018 y 2019 es un hilo en el que reflexiona sobre por qué no es feminista y por qué no iba a participar en la huelga feminista del 8 de marzo de 2018. En él defiende a una mujer y a una familia "tradicional", critica a las falsas denunciantes de violencia de género, las leyes de conciliación y paridad o el aborto. Dice sentirse representada por una "mujer coraje":

"cuya generosidad, responsabilidad y amor se antepone a los intereses y deseos personales y siguen con sus embarazos sin importarles las presiones sociales en las que sólo prima el "Yo,yo,YO". Donde la sociedad pone "YO", ellas ponen VIDA; [...] que han alcanzado sus metas profesionales y laborales sin necesidad de cuotas de "discriminación positiva" [...] las VERDADERAS mujeres maltratadas; [...] NO ME REPRESENTAN aquellas que odian al hombre por el mero hecho de serlo; quienes creen que destruir la esencia de la mujer es feminismo [...]. La lucha no es de género, la lucha es de mujeres frente a niñatas" (@MelisaDRuiz, 02/03/2018).

\section{5. ¿ULTRADERECHA DE "IZQUIERDAS"? ALTER-ACTIVISMO Y POPULISMO DE EXTREMA DERECHA}

La nueva extrema derecha española ha sido consciente, al igual que lo fue la europea, de que alejarse de sus símbolos y formas clásicas era un paso imprescindible para romper la barrera de sus votantes habituales y poder acceder a un electorado más amplio. De la misma manera, Hogar Social y Vox han dado un paso más y han sabido leer las estrategias de la izquierda, tanto de partidos políticos como de movimientos sociales. La gran presentación pública de Vox en la plaza de toros Vista Alegre en Madrid en diciembre de 2018 y su estrategia en los medios de comunicación de masas recuerda en muchos sentidos a lo que hizo hace solo unos años Podemos.

Estudios de la Paz y el Conflicto, Revista Latinoamericana, IUDPAS-UNAH, Volumen 1, Número 2, julio-diciembre 2020, pp. 55-78. DOI: $10.5377 /$ rlpc.v1i2. 9833 
No obstante, Hogar Social ha sido pionero y es especialmente prolijo en la utilización de las tácticas políticas utilizadas hasta ahora por las izquierdas. Quizá la más significativa es la ocupación de edificios, algo típico del movimiento okupa, pero también la utilización de performances y el humor como formas de protesta, algo muy presente en movilizaciones recientes como el 15M (Sierra, 2012). Han hecho representaciones de decapitaciones en la Puerta del Sol de Madrid (lugar emblemático también del 15M) al estilo de DAESH para criticar la política de refugiados, han plantado lápidas en la Castellana de Madrid conmemorando los derechos sociales recortados a los españoles durante la crisis, han realizado campañas contra la contratación de refugiados por parte de Starbucks "\#StarBurka” (@HogarSocial_,08/02/17). e, incluso, se vistieron como los personajes de la serie de la plataforma de streaming Netflix La Casa de Papel para evitar un desahucio. Todas estas acciones se difunden a través de todos los canales que poseen, siendo éste un espacio no mediado habitado especialmente por jóvenes y con la capacidad de maximizar su alcance político.

Pero al igual que el 15M, la nueva extrema derecha usa las plazas. Hogar Social ha sabido combinar de una manera bastante lograda esta doble dimensión del activismo en Internet y la calle. Hacen recogidas de alimentos y repartos solo para españoles, clases particulares para estudiantes, servicio de guardería, biblioteca, asesoría jurídica, pero también celebraciones lúdicas, deportes, senderismo, batidas de limpieza del monte o de reforestación (ÁlvarezBenavides, 2019). Sus acciones son especialmente intensas en los barrios más precarios o con grandes niveles de multiculturalidad de Madrid, Granada, Toledo o Zaragoza. Analizan las necesidades y los problemas específicos de cada lugar y desarrollan campañas adaptadas a la realidad local, lo que ayuda a que su discurso cale entre sus potenciales simpatizantes con mayor facilidad (Jiménez y Álvarez-Benavides, 2019).

Este tipo de estrategias y de acciones recuerdan a muchas de las realizadas por movimientos sociales pretéritos, desde el municipalismo, pasando por el movimiento autónomo, hasta el 15M o a la Plataforma de Afectados por la Hipoteca (PAH). Estaríamos, por tanto, ante una dimensión distinta, tal vez perversa (Toscano, 2017), de la tecnopolítica (Toret, 2013), similar a lo sucedido con los movimientos sociales post-2011 (Pleyers, 2018: 79-90), tanto en su dimensión social como política, en el ámbito local y el internacional. Nos encontramos ante un activismo que alcanza su mayor extensión en las redes, pero que se basa en pequeñas acciones directas en el espacio local, en el que la práctica política transciende el espacio público-privado, imbricándose con el espacio digital (Álvarez-Benavides, 2018). Además, tanto Hogar Social como Vox han sido capaces de desarrollar cada vez más conexiones internacionales, con colectivos y partidos políticos similares tanto de la ultraderecha alternativa como de la convencional. En el caso de Vox, la entrada en las instituciones públicas y, en especial, en el Parlamento Europeo ha sido determinante para la amplificación de estos intercambios.

Todas estas similitudes con las tácticas y acciones de los movimientos sociales y políticos progresistas nos llevan a preguntarnos si se está produciendo lo que Tomás RodríguezVillasante (2014) denomina "desbordes creativos o reversivos", esto es, transformaciones sociales producidas desde la cotidianidad de manera imprevista. Se abandonaría la lógica de la revolución y las grandes movilizaciones y transformaciones sociales, para visibilizar desde lo local, desde lo cotidiano, a través de acciones y situaciones concretas, las contradicciones del sistema. Utilizando las herramientas del "enemigo", transformar desde abajo hacia arriba realidades que se consideran injustas o mejorables. En el caso de Hogar Social la 
contradicción del sistema se plasma en un contexto de salida de la crisis económica en el que muchos españoles continúan viviendo en situación de precariedad (tienen que pedir alimento, ropa, muchos no tienen un hogar), articulando un discurso de culpabilización de la clase política y económica (por permitir un sistema multicultural injusto con los españoles) y con herramientas similares a los movimientos sociales progresistas (no solo mediante la protesta creativa, sino también a través del trabajo cotidiano con estas personas vulnerables), proyectando así un modelo de política y organización social en el que se superan dichas contradicciones.

Del mismo modo, siguiendo con un análisis desde la óptica de las teorías de los nuevos movimientos sociales (Touraine, 1973), de la subjetividad (Wieviorka, 2008) y del alteractivismo (Pleyers, 2018), podríamos definir a Hogar Social como un nuevo movimiento social, al menos como un colectivo activista alternativo, pero de extrema derecha, cuyo proyecto político se plantea a través de acciones de abajo a arriba, en el que las transformaciones sociales se viven y surgen desde la subjetividad, desde concepciones particulares de entender la vida y lo socialmente deseable. De la misma manera que las acciones cotidianas progresistas acaban generando nuevos derechos sociales y articulando una democracia que recoge y reconoce paulatinamente esas prácticas, deseos y derechos subjetivos, esa misma lógica nos llevaría a afirmar que la demanda y la puesta en práctica de otro tipo de "derechos" (de carácter etnocéntrico, racista, homófobo o sexista), podría acabar extendiéndose y repercutiendo en el modelo de democracia, articulándola hacia formas más restrictivas, exclusivas y autoritarias. Los movimientos sociales producen la sociedad, sí, pero no solo "los buenos", y no solo una sociedad "mejor", más inclusiva, más justa y democrática (Pleyers y Álvarez-Benavides, 2019).

En el caso de Vox, con un discurso directo, superando los límites convencionales de lo políticamente correcto y apoyándose en las tácticas comunicativas de la nueva extrema derecha internacional, ha sabido llegar a un electorado desencantado, cuyas identidades han encontrado en su discurso "populista" respuestas directas que, en cierto modo, les han permitido reafirmarse y "empoderarse", al igual que hizo Trump en Estados Unidos (Norris y Inglehart, 2018; Kellner, 2016). De la misma manera que Podemos llegó muy rápido a muchas personas con una coyuntura política, económica e histórica concreta y con un discurso directo, poco convencional y también definido como populista, Vox, en muy poco tiempo y con otra coyuntura histórica singular, ha conseguido tener una creciente relevancia social con un discurso distinto, pero formalmente similar. Así, de la combinación de las estrategias de unos y de otros, y de la lectura del contexto y la forma en el que surgió Podemos, parece que Vox ha encontrado una fórmula para llegar a un electorado cada vez mayor. La desafección hacia la política y los partidos tradicionales, la situación de vulnerabilidad continuada tras la crisis, la ruptura de las instituciones y de los referentes identitarios clásicos, las anomias experimentadas por muchos colectivos de ciudadanos ante la globalización y, evidentemente, el conflicto multidimensional de Cataluña, han hecho que Vox se convierta en un referente en el que encontrar esa identidad perdida o esas respuestas sencillas a problemas complejos. 


\section{LA DOCTRINA DEL SHOCK Y LA BÚSQUEDA DEL ASALTO DEFINITIVO}

La pandemia del COVID-19 (comúnmente conocido como coronavirus) ha sido un episodio más para que la extrema derecha despliegue todos los elementos que han sido determinantes en su reciente auge. Esta nueva crisis ha sido percibida como una nueva oportunidad para aumentar su influencia en las instituciones y apoyo social. Al mismo tiempo, está sirviendo para renovar su discurso y ensayar nuevas tácticas.

En primer lugar, la extrema derecha cuenta con un apoyo popular que jamás había tenido a lo largo del periodo democrático ${ }^{6}$. El crecimiento de Vox desde finales de 2018 a principios de 2020 ha sido enorme si lo comparamos con otros partidos de centro derecha y extrema derecha, españoles y europeos. En las elecciones generales de 2016 obtuvo algo más de 47.000 votos -11.000 votos menos que en 2015 , las primeras elecciones generales a las que se presentaron-, esto es, un $0,2 \%$ de votos (Ministerio del Interior, 2020). Sin embargo, tras las elecciones andaluzas de diciembre de 2018, en las que por primera vez obtuvo representación en un parlamento autonómico (12 diputados y casi 400.000 votos - 10,97\%-), en menos de un año, el partido de ultraderecha sumó más de 2,5 millones de votos $(10,26 \%)$ en las elecciones generales de abril de 2019 y más de 3,5 (15,09\%) en las de noviembre del mismo año (Ministerio del Interior, 2020). En Europa es de los partidos que cuentan con mayor representación parlamentaria por detrás del Partido de la Libertad de Austria (FPÖ) y la Liga Norte en Italia (LN) (Holger y Manow, 2019).

En segundo lugar, una serie de aprendizajes, experiencias y recorridos han posicionado a esta extrema derecha con la capacidad de difundir de manera multidimensional y masiva sus mensajes. Partidos como España 2000 o Plataforma per Catalunya han sido los puentes que han servido para su actualización en la arena política española. La evolución de su imagen y su presentación pública, así como la renovación de su discurso y su equiparación ideológica con la nueva extrema derecha europea, han permitido distanciarla lo suficiente tanto del franquismo como de la extrema derecha violenta de los años 80 y 90 . Las prácticas alteractivistas de colectivos como Hogar Social, que ha sabido leer e imitar a los movimientos sociales y a los nuevos partidos progresistas, ha dotado a la extrema derecha de nuevas técnicas de difusión de su menaje político, captación y socialización de sus miembros. El

\footnotetext{
${ }^{6}$ Es complejo determinar el número de personas que sostienen ideas de extrema derecha en España. Aunque el CIS lleva publicando encuestas sobre autoubicación ideológica desde 1996, éstas se basan en la percepción subjetiva del individuo que contesta a la pregunta, sin recoger ninguna otra variable. Si bien es cierto que la tasa de los que se autodefinen ideológicamente como extrema derecha se ha duplicado si comparamos los barómetros (CIS, 2020a) de principios de 2018 y los de principios de 2020 (aprox. 2\% a 4\%), no representaría siquiera el porcentaje de electores que votó a Vox en las últimas elecciones generales $(15,09 \%)$. Si atendemos a otras encuestas en las que se recogen opiniones sobre la inmigración, la crisis de Cataluña, la utilización de la violencia por parte del estado, por poner algunos ejemplos, podríamos constatar que no es lo mismo apoyar electoralmente a un partido de extrema derecha que defender ciertas ideas propias de la extrema derecha (Álvarez-Benavides, 2018: 65-66). Hay ciertos argumentos del ideario de la extrema derecha internacional que en España han sido sostenidos por partidos más moderados, y que han sido asimilados y normalizados por una parte de la sociedad (Álvarez-Benavides, 2018: 66-70). También es importante tener en cuenta que el partido mayoritario de la derecha española tras la transición ha sido el Partido Popular, refundado a partir de Alianza Popular, que asimiló a buena parte de la extrema derecha franquista (Ignazi, 1992: 13-14), tanto a nivel institucional como social. Muchos de los votos de la extrema derecha española han sido recogidos históricamente por el Partido Popular. Por todo ello, el dato que mejor permite medir el crecimiento de la extrema derecha en España son sus resultados electorales, así como los distintos baremos sobre la intención de voto.

Estudios de la Paz y el Conflicto, Revista Latinoamericana, IUDPAS-UNAH, Volumen 1, Número 2, julio-diciembre 2020, pp. 55-78. DOI: $10.5377 /$ rlpc.vli2.9833
} 
contexto internacional y la experiencia de otras organizaciones radicales, como la alt-right americana, han posibilitado la articulación y el abordaje de temas clásicos de una manera novedosa, directa y efectiva. La experiencia en Internet y las redes sociales, tanto de los distintos colectivos como de muchos simpatizantes más jóvenes, han ido generando herramientas para equipararse en la arena política digital con otros partidos políticos hasta ahora dominantes.

Finalmente, el contexto de tensión política previo, que ha tenido como colofón la crisis del COVID-19, ha servido para dar alas a estas organizaciones políticas. El crecimiento de Vox coincide con el proceso de independencia de Cataluña, la moción de censura que acabó con el gobierno del Partido Popular debido a los casos de corrupción del partido, la desafección de la ciudadanía hacia la clase política agravada por la repetición de las elecciones generales en 2019 y la incapacidad de sumar mayorías parlamentarias para formar un gobierno. Además, la formación de un gobierno de coalición liderado por el Partido Socialista Obrero Español (PSOE) con ministros de Unidas Podemos, dos de ellos pertenecientes a Izquierda Unida, movimiento en el que participa el Partido Comunista de España (PCE), han alentado las posiciones políticas más radicales en la sociedad española.

El discurso desmedido y directo de la extrema derecha española, la utilización de bulos, fake news, exageraciones, chivos expiatorios y la normalización de la postverdad como herramienta de comunicación se ha ido magnificando. Uno de los ejemplos más significativos de esta progresión discursiva previa a la crisis se produjo cuando Twitter suspendió la cuenta de Vox por incitación al odio por publicar un tweet en el acusaba al gobierno de promover la pederastia. El partido de ultraderecha aprobó una medida en Murcia por la que los padres se podían negar a que sus hijos recibieran charlas sobre diversidad sexual e igualdad de género (el denominado "pin parental"). La portavoz del gobierno publicó un tweet en el que afirmaba que Vox no soportaba la diversidad y no respetaba al colectivo LGTBI, a lo que los responsables de redes sociales de este partido contestaron: "lo que no soportamos es que [...] con dinero público promováis la pederastia" (@VOX_es 18/01/20).

Todo este bagaje ha dotado a la extrema derecha española de las herramientas para liderar una campaña que pretende instrumentalizar políticamente una situación tremendamente compleja, a través de la creación de una sensación de caos hiperbolizada. Se pretende, desde el miedo y el shock generalizado, imponer una agenda política, superar a otras fuerzas dentro del espectro político de derechas y derrocar el gobierno electo. Naomi Klein analizaba en La Doctrina del Shock (2012) cómo en momentos de contingencia y crisis en distintas partes del planeta se habían aprobado medidas impopulares que coincidían con la agenda neoliberal. La conclusión que se puede extraer de este trabajo es sencilla: cuando se produce un acontecimiento que genera inseguridad, incertidumbre y miedo, los individuos aceptamos con menos resistencia medidas políticas y económicas que no toleraríamos en momentos de normalidad. Estas crisis, que pueden ser económicas, políticas, medioambientales o de cualquier tipo, son aprovechadas por las élites políticas y económicas neoliberales, los llamados capitalistas del desastre, para imponer su ideario. Esta tesis se complementa con el paradigma ya clásico de la sociedad del riesgo establecido por Anthony Giddens, que dibuja una modernidad en la que la sociedad vive más en el futuro que en el presente, o en la fragilidad de ese futuro incierto (Giddens, 1993), y, sobre todo, por Ulrich Beck, que pone el foco en el modo en el que la sociedad gestiona esa inseguridad. El riesgo posibilita políticas de control del riesgo, que a su vez modifican la percepción de la realidad, las estructuras 
sociales, la concepción del trabajo, las relaciones sociales y, por supuesto, la política (Beck, 1992).

Durante la crisis del coronavirus se ha establecido un nuevo nivel de agresividad política como estrategia comunicativa en un contexto en el que una sociedad de riesgo como la española se encuentra en estado de shock. El ideario antinmigración, antifeminista, antidiversidad (en el sentido amplio ya explicado) y económicamente neoliberal -en el caso de Vox-, pretende normalizarse como la alternativa más viable para la salida de la crisis y la recuperación de la normalidad. Para ello, la radicalidad discursiva y los bulos propagados por la extrema derecha y compartidos por sus ahora millones de seguidores, han combinado su ideario político con la crítica al gobierno, en un momento en el que la ciudadanía ha estado más conectada que nunca a los canales de información, tanto a los nuevos como a los tradicionales. Días antes de que estallara la crisis y que se declarara el estado de alarma el 14 de marzo de 2020, se celebró la manifestación feminista del 8 de marzo. Esa misma jornada Vox organizó un mitin-contramanifestación antifeminista- y Hogar Social participó activamente en las redes sociales en contra de la manifestación. Lo más significativo de este hecho es que la cercanía de la manifestación con el estallido de la crisis se configuró como el primer argumento para la difusión masiva de bulos para atacar al gobierno -y de paso a las participantes del evento-. El 10 de marzo de 2020 la cuenta oficial de Vox publicaba un vídeo en el que Santiago Abascal afirmaba que "Pedro Sánchez, ha mentido a los españoles y ha ocultado información. Este es un Gobierno que ha ido con guantes de látex a una manifestación mientras afirmaba a los españoles que no tenían que tomar medidas y que los focos estaban controlados"7. También se ha vinculado la pertenencia de varios miembros del gobierno al partido socialista y al partido comunista español con la pretensión de imponer su ideología política a raíz de la crisis, todo ello hilado con un discurso racista, esta vez dirigido hacia los chinos por su supuesta responsabilidad en la expansión de la pandemia. En una entrevista en Televisión Española (TVE) el 13 de abril, Macarena Olona, diputada de Vox, afirmó: "China nos ha traído dos cosas: en primer lugar, la peste del siglo XXI y, en segundo lugar, el caldo de cultivo propicio para que los postulados comunistas se impongan en nuestro país" (@Desayunos_tve, 13/04/20). Esa misma diputada, en una intervención en el parlamento, se refirió al presidente del gobierno como "Pedro el sepulturero", haciendo un guiño a un hastag (\#pedroelsepulturero) que circuló entre las cuentas de ultraderecha desde comienzos de la crisis con el propósito de hacerlo responsable de las víctimas provocadas por el virus. La arenga antinmigración sigue presente en ambos colectivos, puesto que Hogar Social ha continuado excluyendo a los "no españoles" de sus acciones de ayuda social (lo que ha publicitado en todos sus canales en redes) y Vox, pidió, por ejemplo, eliminar la sanidad universal y gratuita para los inmigrantes no regularizados durante la pandemia (@Vox_es, 24/03/20). También la actitud mesiánica, en la que Vox se presenta como salvador de un país en ruina sanitaria, social, política y económica, demandando la dimisión del gobierno y reclamando la formación de un gobierno de concentración y emergencia nacional del que formarían parte (González, El País, 31/03/20).

La difusión del discurso de extrema derecha va más allá de las propias organizaciones, pues se nutre de una prensa y grupos mediáticos de difusión masiva afines, como Libertad Digital y Okdiario, de influencers y youtubers de extrema derecha, y de la sintonía discursiva

\footnotetext{
${ }^{7}$ Los guantes de látex morados son una indumentaria habitual en las manifestaciones feministas y las ministras del gobierno los llevaron durante una parte de la manifestación.

Estudios de la Paz y el Conflicto, Revista Latinoamericana, IUDPAS-UNAH, Volumen 1, Número 2, julio-diciembre 2020, pp. 55-78. DOI: 10.5377/rlpc.v1i2.9833
} 
e ideológica, en ocasiones, de sectores de la derecha convencional española, como el Partido Popular y otros partidos políticos, asociaciones, colectivos, medios y periodistas conservadores o cercanos a la derecha. De hecho, esta radicalidad discursiva está siendo imitada durante la crisis por algunos representantes políticos de otros partidos de derecha, lo que la convierte en una estrategia política que se intuye como efectiva electoral y socialmente. Todo ello, con una base social en las redes cada vez más activa, capacitada y organizada. Ya no se trata exclusivamente de personas mayores nostálgicas del franquismo, o de ultras y skin heads vinculados a equipos de fútbol y otros colectivos minoritarios. Su capacidad de influencia ha crecido y su utilización de medios digitales es una razón explicativa de peso. En las últimas elecciones Vox fue el partido que más impacto tuvo en la ciudadanía a través de las redes sociales y los canales digitales (CIS, barómetro de enero de 2020). Hogar Social sigue combinado su actividad en las calles con sus actividades en las redes, ahora con página web, un canal de video y más presencia y seguidores en las redes sociales. Cada vez hay más cuentas y más medios en los que la extrema derecha se prodiga en su actividad comunicativa. Un escenario distópico, con una población en shock, pretende ser utilizado como un caldo de cultivo perfecto para sumar más apoyos y normalizar el discurso neofascista.

\section{CONCLUSIONES}

Antes de 2018 ningún dato hacía pensar que la extrema derecha podía lograr representatividad en España a través de un partido político. Su desarrollo en Europa y en el resto del mundo parecía no afectar a nuestro país. No obstante, en apenas un año, se ha convertido en una realidad con una perspectiva de progresión tan incierta como preocupante. Más allá de los principales motivos del crecimiento de estas nuevas derechas, lo cierto es que desde comienzos del nuevo milenio se han producido cambios que se han acabado convirtiendo en los cimientos de, al menos, dos nuevas ultraderechas.

Aunque ni Hogar Social ni Vox se reconocen como extrema derecha o colectivos afines, hay muchos elementos comunes en su ideario que eclipsa su diferencia fundamental, la ideología económica, la de Vox neoconservadora y ultraliberal, y la de Hogar Social, estatalista, autárquica y con "fines sociales". Las similitudes son especialmente reconocibles en su discurso político basado en la exaltación de lo español, en la reivindicación de un pasado y una tradición abandonada en una crítica acérrima a la diversidad (en su sentido más amplio), responsable de la pérdida de todos los logros alcanzados en la historia de la nación española.

Para articular este discurso, ambas formaciones han acudido a nuevas estrategias. La primera de ellas es la difusión abierta y multidimensional de su ideología a través de los medios de comunicación tradicionales, los distintos canales digitales, las redes sociales, así como una presencia activa en el espacio público local, también en el internacional, conectados con otros partidos y colectivos similares. Otra estrategia compartida ha sido el progresivo "lavado de cara", eliminando y evitando la simbología que les relacione con el franquismo o la extrema derecha tradicional. Por último, estas organizaciones también comparten la utilización de tácticas y discursos que previamente habían sido utilizados por los movimientos sociales y partidos políticos progresistas y de izquierdas. No solo se han fijado en lo que han hecho otros colectivos de extrema derecha, sino que además han sabido 
leer e imitar lo que han hecho otros movimientos sociales como el movimiento antiglobalización, el movimiento autónomo o el 15M, al igual que partidos políticos como Podemos.

Todo ello dibuja un panorama político completamente distinto al que se soslayaba a comienzos de esta década, en la que brotaron toda una serie de movimientos sociales que reclamaban más justicia social, más dignidad y una mayor y mejor democracia. A pesar de las enormes diferencias que existen con respecto a estos movimientos sociales y partidos políticos, muchos de los marcos teóricos que utilizamos para explicar cómo surgieron, cómo se articularon y cómo estaban transformando la realidad política y social pueden ser utilizados de manera análoga para analizar a las nuevas ultraderechas y la sociedad futura que podrían dibujar.

Pocos meses antes del 15M y de todos los movimientos hermanos que surgieron antes y después, Benjamín Tejerina publicaba La Sociedad Imaginada (2010) donde, desde una perspectiva histórica y de manera meticulosa, analizaba cómo las divisiones entre lo público y lo privado se habían vuelto difusas, cómo las identidades particulares habían ido generando identidades colectivas cada vez más plurales y cómo, a través de las protestas, las movilizaciones y la socialización, los movimientos sociales habían conseguido transformar la realidad, en este caso la española, alcanzando algunas de sus reclamaciones y edificando, al menos en parte, esa sociedad que imaginaron. Nos preguntamos si la sociedad que imaginan los nuevos movimientos sociales y los partidos políticos de extrema derecha, que surge de identidades individuales que se articulan a su vez en identidades colectivas, que experimentan y practican en sus vidas cotidianas, se está construyendo poco a poco, a través de procesos de subjetivación y de empoderamiento. Hablaríamos así de una verdadera revolución silenciosa, más en el sentido de Ignazi (1992) que en el de Inglehart (1977), en el que la extrema derecha avanza retrocediendo: reconquistando derechos particulares, eliminado derechos universales.

La crisis del COVID-19 se ha presentado como un escenario inigualable para poner en práctica de manera organizada, sistemática y con una intensidad inusitada todo lo aprendido y ensayado durante los últimos años. Con millones de seguidores en España, transformados en multiplicadores exponenciales de sus mensajes, en un contexto de inseguridad y caos, de desconocimiento absoluto sobre el presente y sobre el futuro, la extrema derecha española ha entendido el miedo, el aturdimiento y el shock generalizado como una oportunidad única para tratar de dar el salto definitivo, imponer su agenda política y hacer real su sociedad imaginada.

\section{REFERENCIAS}

Albanese, M. et al. (2014). Fascsti di un Alter Millennio? Crisi e Partecipazione in CasaPound Italia. Catania: Bonano.

Allcott, H. y Gentzkow, M. (2017). "Social Media and Fake News in the 2016 Election", Journal of Economic Perspectives, 31 (2), American Economic Association, 211236. Disponible en: https://doi.org/10.1257/jep.31.2.211

Alonso, S. y Rovira, C. (2015). "Spain: No Country for the Populist Radical Right?", South European Politics and Society, 20, Taylor \& Francis Online, 21-45. Disponible en: https://doi.org/10.1080/13608746.2014.985448

Estudios de la Paz y el Conflicto, Revista Latinoamericana, IUDPAS-UNAH, Volumen 1, Número 2, julio-diciembre 2020, pp. 55-78. DOI: 10.5377/rlpc.v1i2.9833 
Álvarez-Benavides, A. (2018). "Fascism 2.0: the Spanish Case", Digitcult Sientific Journal on Digital Cultures, 3 (3), Roma: Guglielmo Marconi University, 61-74. Disponible en: http://dx.doi.org/10.4399/97888255208976

Álvarez-Benavides, A. (2019). "Elementos para el análisis de la nueva extrema derecha española”. En Rubén García y Gomer Betancor (Eds.), Movimientos sociales, acción colectiva y cambio social en perspectiva. Continuidades y cambios en el estudio de los movimientos sociales. Abadiño: Fundación Betiko. 59-69.

Anderson, B. (1991). Imagined Communities: Reflections on the Origin and Spread of Nationalism. Londres: Verso. Disponible en: https://doi.org/10.1093/fmls/cqp012

Beck, U. (1992): Risck Society. Towards a New Modernity. Londres: Sage Publications.

Caiani, M. y Parenti, L. (2013). European and American Extreme right groups and the Internet. Farnham: Ashgate. Disponible en: https://doi.org/10.4324/9781315580845

Casals, X. (2011). "La extrema derecha europea: una tendencia ascendente", Anuari del Conflicte Social, 1 (1), Barcelona: Observatorio del Conflicto Social, 389-401.

Casals, X. (2015). “¿Por qué los obreros apoyan a la ultraderecha? Diez reflexiones para elaborar una respuesta", Working Papers, 341, Barcelona: Institut de Ciències Polítiques y Social.

Castells, M. (2012). Networks of Outrage and Hope. Social Movements in the Internet Age. Cambridge: Polity Press. Disponible en: https://doi.org/10.1080/1369118X.2013.829514

Centro de Investigaciones Sociológicas (2019). Barómetro de enero. (Estudio no 3.238). Recuperado de: http://www.cis.es/cis/opencm/ES/1 encuestas/estudios/ver.jsp?estudio=14442

Centro de Investigaciones Sociológicas (2019). Barómetro de julio. (Estudio no 3.257). Recuperado de: http://www.cis.es/cis/export/sites/default/Archivos/Marginales/3240_3259/3257/es3 257mar.pdf

Centro de Investigaciones Sociológicas (2020). Barómetro de enero. (Estudio no 3.271). Recuperado http://www.cis.es/cis/opencms/ES/NoticiasNovedades/InfoCIS/2020/Documentacio n 3271.html

Centro de Investigaciones Sociológicas (2020a) Centro de Investigaciones Sociológicas. Series históricas sobre autoubicación ideológica. Recuperado de: http://www.cis.es/cis/opencms/ES/11 barometros/Indicadores PI/ideologica.html60 10040.html

Constitución Española (1978). Título V. De las relaciones entre el Gobierno y las Cortes Generales Artículo 116.

Di Nunzio, D. y Toscano, E. (2011). Dentro e Fuori CasaPound. Roma: Armando.

Enli, G. (2017). "Twitter as arena for the authentic outsider: exploring the social media campaigns of Trump and Clinton in the 2016 US presidential election", European Journal of Communication, 32(1), 50-61. Disponible en: https://doi.org/10.1177/0267323116682802

European Parliament (2019). European elections. Recuperado de: https://election-results.eu Gallego, F. (2007). Neofascistas: Democracia y extrema derecho en Francia e Italia. Barcelona: Debolsillo. 
Givens, T. E. (2004). “The radical right gender gap", Comparative Political Studies, 37 (1), SAGE Journals, 30-54. Disponible en: https://doi.org/10.1177/0010414003260124

González-Enríquez, C. (2017): La excepción española: el fracaso de los grupos de derecha populista pese al paro la desigualdad y la inmigración. En: Working Paper, 7/2017, Madrid: Real Instituto Elcano, 1-41.

Guidens, A. (1993). Consecuencias de la modernidad. Madrid: Alianza Editorial.

Hernández-Carr, A. (2011). "La derecha radical populista en Europa: discurso, electorado y explicaciones", Revista Española de Investigaciones Sociológicas, 136, Madrid: CIS, 141-160.

Hine, C. (2004). Etnografía virtual. Barcelona: Editorial UOC.

Hobsbawm, E. y Ranger, T. (2012). La invención de la tradición. Barcelona: Crítica.

Holger, D. y Manow, P. (2019). Parliaments and Governments Database ( ParlGov): Information on Parties, Elections and Cabinets in Modern Democracies. Recuperado el 23 Noviermbre, 2019, de: http://www.parlgov.org/.

Hooley, T.; Marriott, J. y Wellens, J. (2012). What is online research? Using the Internet for Social Science Research. Londres: Blomsbury. Disponible en: http://dx.doi.org/10.5040/9781849665544

Hutchinson, J. (2019). The New-Far-Right Movement in Australia. Terrorism and Political Violence, 1-23. Disponible en: https://doi.org/10.1080/09546553.2019.1629909

Ibáñez, J. (1985). "Análisis sociológico de textos y discursos". Revista de Investigaciones Sociológicas, 1, 119-162.

Ignazi, P. (1992). "The silent counter-revolution Hypotheses on the emergence of extreme right-wing parties in Europe", European Journal of Political Research, 22, Wiley, 334. Disponible en: https://doi.org/10.1111/j.1475-6765.1992.tb00303.x

Ignazi, P. (2003). Extreme Right Parties in Western Europe. Oxford: Oxford University Press. Disponible en: https://dx.doi.org/10.1093/0198293259.001.0001

Inglehart, R. (1977). The Silent Revolution. Changing Values and Political Styles Among Western Publics. New Jersey: Princeton University Press.

Jiménez Aguilar, F. y Álvarez-Benavides, A. (2019). “Asociaciones Culturales de Ayuda Nacional. La emergencia de una extrema derecha alternativa en España", Tiempo Devorado. Revista de Historia Actual, 6 (1), Barcelona: Universitat Autònoma de Barcelona, 54-83.

Kellner, D. (2016). American Nightmare: Donald Trump, Media Spectacle, and Authoritarian Populism. Rotterdam: Sense Publishers.

Kelly, A. (2017). "The Alt-Right: Reactionary rehabilitation for white masculinity", Soundings, 66, Lawrence \& Wishart, 68-78. Disponible en: https://doi.org/10.3898/136266217821733688

Klein, N. (2012). La doctrina del shock: el auge del capitalismo del desastre. Barcelona: Planeta.

Kozinets, R. (2010). Netnography: The Marketer's Secret Weapon. Mountain View: White Paper.

Lockie, S. (2017). "Post-Truth Politics and the Social Sciences", Environmental Sociology, 3 (1), Londres: Taylor \& Francis Online, 1-5. Disponible en: https://doi.org/10.1080/13569317.2016.1150136

Mayer, N. (2018). "El Auge de la Extrema Derecha en Europa: El Caso del Frente Nacional en Francia", Anuario internacional CIDOB, 241-249.

Estudios de la Paz y el Conflicto, Revista Latinoamericana, IUDPAS-UNAH, Volumen 1, Número 2, julio-diciembre 2020, pp. 55-78. DOI: 10.5377/rlpc.v1i2.9833 
Merkl, P. (1997). "Introduction”. En Merkl, P. y Weinberg, L. (Eds.), The Revival of RightWing Extremism in the Nineties. Londres: Frank Cass, 1-16. Disponible en: https://doi.org/10.4324/9781315037639

Metroscopia (2018). Estimación de voto elecciones generales de octubre. Recuperado de: http://metroscopia.org/el-momento-vox/

Ministerio de Presidencia (2019). Informes anuales sobre asesinatos por violencia machista del Ministerio de la Presidencia, Relaciones con las Cortes e Igualdad. Recuperado de: $\quad$ http://www.interior.gob.es/web/servicios-al-ciudadano/violencia-contra-lamujer/estadisticas

Ministerio del Interior (2020). Consulta de Datos Electorales. Recuperado de: http://www.infoelectoral.mir.es/infoelectoral/min/

Mudde, C. (2007). Populist Radical Right Parties in Europe. Cambridge: Cambridge University Press. Disponible en: https://doi.org/10.1017/CBO9780511492037

Nagle, A. (2017). Kill All Normies. Online Culture Wars from 4chan and tumblr to Trump and the Alt-right. Londres: Zero Books.

Norris, P. e Inglehart, R. (2018). Cultural backlash: Trump, Brexit, and the rise of authoritarian populism. New York: Cambridge University Press. Disponible en: https://doi.org/10.1017/9781108595841

Panelconfindecial (2018). Cuarta oleada. IMOP Insights. Diciembre. Recuperado de: https://www.elconfidencial.com/espana/barometro-panel-encuestas-votos-politicasocial/especial/)

Pérez-Agote, A. (1993). “Las paradojas de la nación”, Revista Española de Investigaciones Sociológicas, 61, Madrid: CIS, 7-21.

Pink, S. et al. (2016). Digital Ethnography: Principles and Practice. Londres y Los Ángeles: SGAE. Disponible en: https://doi.org/10.1177/1461444817733962c

Pleyers, G. (2018). Movimientos sociales en el siglo XXI. Perspectivas y herramientas analíticas. Buenos Aires: CLACSO.

Pleyers, G. y Álvarez-Benavides, A. (2019). "La producción de la sociedad a través de los movimientos sociales", Revista Española de Sociología, 28 (1), Madrid: Federación Española de Sociología, 141-149. Disponible en: https://doi.org/10.22325/fes/res.2018.53

Rodríguez-Villasante, T. (2014). Redes de vida desbordantes. Fundamentos para el cambio desde la vida cotidiana. Madrid: Editorial Catarata.

Rodríguez, J. (2012). "Historia de un Fracaso y ¿de una refundación?: de la vieja a la nueva extrema derecha En España (1975-2012)", Studia Histórica. Estudios de Historia Contemporánea, 30, Salamanca: Universidad de Salamanca. 231-268

Sánchez, J. y Rodríguez, S. (2013). "La extrema-derecha en Facebook. España 2000 y Democracia Nacional durante la campaña electoral de 2011”, Revista Mediterránea de Comunicación, 4 (1), Alicante: Universidad de Alicante, 221-258.

Sebastián, J. (2018). ;Identitarios de Europa, Uníos! Tarragona: Fines ediciones.

Sierra, S. (2012). "Humor y crítica social en la red en el entorno del 15M", Discurso \& Sociedad, 6 (3), Barcelona: Centre of Discourse Studies. 611-635.

Sociométrica (2019). Perfil del votante de Vox. Mayo. Recuperado de: https://www.elespanol.com/espana/politica/20190503/vox-solo-votantes-mujeresunidas-podemos-paso/395461331 0.html 
Tejerina, B. (2010). La sociedad imaginada. Movimientos sociales y cambio cultural en España. Madrid: Trotta.

Toret, J. (2013). Tecnopolítica: la potencia de las multitudes conectadas. El sistema red 15M, un nuevo paradigma de la política distribuida. Barcelona: UOC. Disponible en: http://dx.doi.org/10.7238/in3wps.v0i0.1878

Toscano, E. (2017). "The Dark Side of Web-Activism: The Case of CasaPound Italia". En: Francesco Antonelli (Ed.) Net-activism. How digital technologies have been changing individual and collective actions. Roma: Roma TrE-Press, 81-87.

Toscano, E. (2019). Researching Far-Right Movements: Ethics, Methodologies, and Qualitative Inquiries. Londres: Routledge. Disponible en: https://doi.org/10.4324/9780429491825

Touraine, A. (1973). Production de la société. Paris: Seuil.

Vázquez, A. (2008). Ciberantropología: Cultura 2.0. Barcelona: Editorial UOC.

Weld, K. (2020). "Holy War: Latin America's Far Right". Dissent, 67 (2), 57-65.

Wieviorka, M. (2008). Neuf leçons de sociologie. Paris: Robert Laffont.

Notas de prensa, referencias online y publicaciones en redes sociales

@Desayunos_tve. Publicación de Twitter. 13 de abril de 2020, 3:29 p.m. https://twitter.com/Desayunos tve/status/1249600688302313472

@HogarSocial_Publicación de Twitter. 8 de febrero de 2017, 4:08 p.m. https://twitter.com/HogarSocial_/status/829255667898843136

@HogarSocial_ Publicación de Twitter. 17 de agosto de 2017, 1:53 p.m. https://twitter.com/HogarSocial/status/898241407663689728

@ HogarSocialTol. Publicación de Twitter. 29 de agosto de 2018, 5:53 a.m. https://twitter.com/HogarSocialTol/status/1034740823701839873

@MelisaDRuiz. Publicación de Twitter. 2 de marzo de 2018, 9:58 a.m. https://twitter.com/MelisaDRuiz/status/969588132730626048

@Santi_ABASCAL. Publicación de Twitter. 16 de septiembre 2014, 5:31 a.m. https://twitter.com/santi abascal/status/511990735315685376

@Santi_ABASCAL. Publicación de Twitter. 19 de noviembre 2015, 4:45 a.m. https://witter.com/Santi_ABASCAL/status/667277556517888000

@Santi_ABASCAL. Publicación de Twitter. 1 de octubre de 2018, 3:23 p.m. https://twitter.com/Santi_ABASCAL/status/1046847778519965702

@Santi_ABASCAL. Publicación de Twitter. 28 de noviembre 2018, 10:11 a.m. https://twitter.com/Santi_ABASCAL/status/1067798158506369024

@Santi_ABASCAL. Publicación de Twitter. 9 de diciembre de 2018, 3:04 p.m. https://twitter.com/Santi_ABASCAL/status/1071858154118492160

@vox_es. Publicación de Twitter. 18 de enero de 2020, 02:24 a.m. Tweet borrado por incumplir las normas de Twitter por incitar al odio. Se puede visionar en: https://m.europapress.es/andalucia/noticia-federacion-andaluza-asociaciones-lgtbiquerellara-contra-vox-decir-tuit-promoveis-pederastia-20200120153218.html

@vox_es. Publicación de Twitter. 24 de marzo de 2020, 1:35 p.m. https://twitter.com/vox_es/status/1242505450836365316 
@voxnoticias_es. Publicación de Twitter. 12 de noviembre 2018, 10:11 a.m. https://twitter.com/voxnoticias es/status/1061917901031129088? s=21 -tweet parcialmente borrado por una denuncia del titular de los derechos de autor-

\#pedroelsepulturero. $\quad$ Etiqueta (hastag) de Twitter. https://twitter.com/search?q=\%23pedroelsepulturero\&src=typed query

\#StarBurka. Etiqueta (hastag) de Twitter. https://twitter.com/search?q=\%23StarBurka\&src=typed query

Arjona, A. (2018, Octubre 10). Entrevista Santiago Abascal líder de Vox. Radio Cope. Recuperado el 8 de enero, 2019 de https://copecdnmed.agilecontent.com/resources/mp3/6/8/1539213781286.mp3?download

Bans, G. (2018, Octubre 4). "Entrevista a Santiago Abascal". Intereconomía, 4 de octubre. $\begin{array}{llllll}\text { Recuperado el } & 9 & \text { de } & \end{array}$ https://www.youtube.com/watch?v=YBSoFE3aciU

González, M. (2020, Marzo 31). Vox reclama la dimisión de Pedro Sánchez y la creación de un Gobierno de “emergencia nacional”. El País. Recuperado el 31 de marzo, 2020. https://elpais.com/espana/2020-03-31/vox-reclama-la-dimision-de-pedro-sanchez-yla-creacion-de-un-gobierno-de-emergencia-nacional.html

Hogar Social. Publicación de Facebook. 31 de octubre de 2016. https://esla.facebook.com/HogarSocial1/photos/combate-al-enemigo-imbatibleya-estádisponible-la-nueva-camiseta-de-hsmpodéis-ad/1176174762467248/

Hogar Social Granada. Publicación de Facebook. 20 de septiembre de 2018. https://www.facebook.com/HogarSocialGranada/posts/342284043185885

La Contra TV. (2017, Agosto). Melisa: "La de Hogar Social Madrid es una historia de éxito". Entrevista a Melisa de Hogar Social. -Borrado de Youtube.com-. Recuperado el 6 de agosto, 2019 de: https://www.ivoox.com/melisa-la-hogar-social-madrid-es-unaaudios-mp3 rf 17617324 _.html

Martínez, J. (2019, Febrero 4). Conversaciones en el diván. Rafael Bardají, ideólogo de Vox". El Mundo. Recuperado el 4 de febrero, 2019 de: https://www.elmundo.es/espana/2019/02/04/5c573d29fc6c8355328b4619.html

VOX España. \#PorEspaña "Espíritu de reconquista" Santiago Abascal en Covadonga. Video de Youtube publicado el 13 de abril de 2019. https://youtu.be/FGP 9PHAq2M

\section{REFERENCIA DE LOS AUTORES}

Antonio Álvarez-Benavides es Doctor en Sociología por la Universidad Complutense de Madrid y por la Ecole des Hautes Etudes en Sciences Sociales de París. Actualmente es profesor en la Universidad de la Ciudad de Nueva York (CUNY) e investigador en el Centre d'Analyse et d'Intervention Sociologiques (CADIS-Internacional) y en el Grupo de Estudios Socioculturales Contemporáneos (GRESCO-UCM). Ha sido profesor en la UC3M, la UVA, la UNED, y en la UNIR, y ha participado en más de veinte proyectos de investigación e intervención social en el ámbito público y privado, a nivel nacional e internacional. Cuenta con una veintena de publicaciones y colaboraciones en libros. Sus trabajos abordan la sociología de los movimientos sociales, la teoría sociológica, la sociología de las migraciones y la intervención social. alvarezbenavides@gmail.com ORCID: 0000-0002-4346-2219. 
Francisco Jiménez Aguilar es doctorando en el programa de Historia y Artes de la Universidad de Granada. Es graduado en historia (2015), con maestrías en Historia de Europa y América (2016), Investigación para la paz y análisis de conflictos (2017) y Formación del Profesorado (2018). $\mathrm{Su}$ investigación se centra en la historia de las mujeres y de género, la dictadura franquista y la extrema derecha. fjja@,correo.ugr.es. ORCID: 0000-0002-61945089. 